\title{
Research on Performance Quality Prediction Method of Missile Based on Grey Theory and SVM
}

\author{
Rui Huang*, Xiaofang Liu and Xiang Zheng \\ Department of Management, High-Tech Institute of Xi'an 710025, Shaanxi, China \\ ${ }^{*}$ Corresponding author
}

\begin{abstract}
Accurately grasping the performance quality status of the missile is a prerequisite for ensuring the completion of the operational task. At present,in a real missile launch exercise,in order to ensure the success of the launch,the method of fist passing the test and then launching is usually adopted.This method can hardly meet the large-scale,high-volume and highefficiency operational requirements in the future battlefield.In order to meet the future operational requirements,based on the past test data of the performance parameters of the missile and the information of daily management and stored,combined the information of actual missile launch results,this paper uses grey theory,linear weighted comprehensive evaluation and SVM to accurately predict the performance quality status of the missile, and provide technical support for operational decisionmaking.
\end{abstract}

Keywords-grey theory; linear weighted; SVM; quality prediction

\section{INTRODUCTION}

The effect of the missile mainly depends on the status of its own performance and quality, and the performance quality of the missile is accurately mastered, which plays an important role in the operation and management decision of the army. At present, in the real missile launching rehearsal, the launching missile is tested first, and the launch is carried out after the test confirms that the performance quality of the missile is qualified. Because the missile is a multilevel complex weapon system, the data parameters are numerous and the test time consuming and energy consuming, which takes up a lot of time during the whole practice. However, in the future joint operations, the missile forces are inevitably faced with large-scale and efficient operations. If we still use the mode of launching after testing the missile first, we will surely bungle the chance of winning a battle. Therefore, accurate prediction of the missile's performance quality status is the inevitable requirement for the missile troops, and is also of great significance for the future joint operations.

This paper, based on the test data of missile performance parameters and daily management and storage information, combined with the result information of live launch, uses grey theory, linear weighted comprehensive evaluation and support vector machine to predict the performance quality status of missile performance parameters, subsystems and whole missile system in turn. It provides a way for prediction of missile performance quality status.

\section{PREDICTION IDEAS}

First, the grey prediction has the advantages of few samples, simple calculation and high precision of short-term prediction. The effect is better for small data samples and single step prediction [1,2]. Although the data amount of the whole missile is very large, the amount of data to a single parameter is still very small. Therefore, we can use grey theory to predict the parameters data of missile based on the information collected in the past.

Secondly, the linear weighted comprehensive evaluation method has the advantages of easy calculation, easy to apply and popularize. It can evaluate the performance quality status of subsystems of the missile by the method of linear weighted comprehensive evaluation according to the prediction results of the parameters and the daily management and storage information.

Finally, the support vector machine (SVM) has a mature theoretical basis, and its generalization performance is very good. It has strong advantages in dealing with the nonlinear high dimensional number and local minima of small sample data, and can be extended to other machine learning problems, such as function fitting [3]. The support vector mechanism can be used to build a model to establish the relationship between the missile launching result information and the performance quality status of subsystems, so as to realize the reliable prediction of the performance quality status of the missile to be launched.

The prediction process of the performance quality status of the missile is shown in Figure 1. 


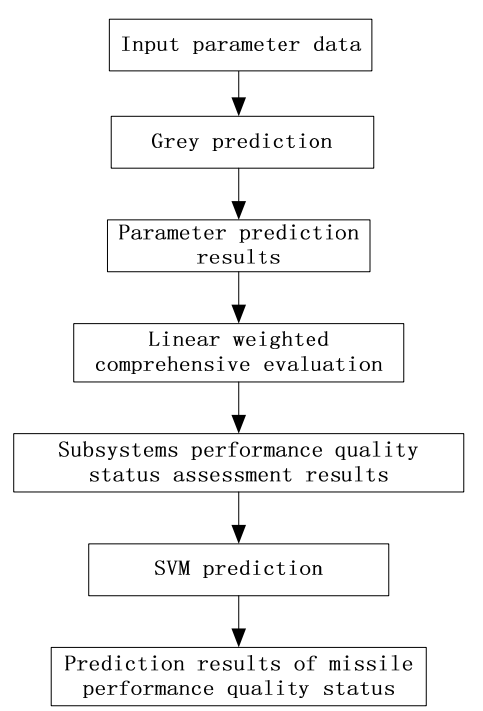

FIGURE I. FLOW CHART OF MISSILE PERFORMANCE QUALITY STATUS PREDICTION

\section{Prediction of Missile Performance Parameters BASED ON GREY THEORY}

Taking the performance parameter $\mathrm{A}$ of a missile warhead as an example, the GM $(1,1)$ prediction model is selected for 3 years' prediction (test data of parameter A refer to table 1).

\section{TABLE I. WARHEAD-PARAMETER A TEST DATA COLLECTION}

\begin{tabular}{|c|c|c|c|}
\hline \multicolumn{4}{|c|}{ Parameter A test data } \\
\hline measured value & test times & $\ddot{\mathrm{y}}$ & $\ddot{y}$ \\
\hline 0.084 & 1 & & \\
\hline 0.085 & 2 & & \\
\hline 0.084 & 3 & & \\
\hline 0.083 & 4 & & \\
\hline 0.084 & 5 & & \\
\hline
\end{tabular}

\section{A. Prediction Process}

a. Suppose $X^{(0)}$ is a sequence of non negative raw data, $\quad X^{(0)}=\left\{x^{(0)}(1), x^{(0)}(2), \cdots, x^{(0)}(n)\right\} \quad$, where $\quad x^{(0)}(i)$ corresponds to the output of the system at the time.

$$
X^{(0)}=(0.084,0.085,0.084,0.083,0.084)
$$

b. A grey cumulative for $X^{(0)}$ is used to get a new generated data sequence $X^{(1)}$.

$$
X^{(1)}=(0.084,0.169,0.253,0.336,0.420)
$$

c. The grey model GM $(1,1)$ is established from the new data sequence $X^{(1)}$, and the corresponding albino differential equation is

$$
\frac{d x^{(1)}(t)}{d t}+a x^{(1)}(t)=b
$$

Grey differential equation is:

$$
x^{(0)}(k)+a z^{(1)}(k)=b
$$

Among them, a is the development coefficient, $b$ is the grey function, and $z^{(1)}(k)$ is the background value of $x^{(1)}(k)$ on $[k-1, k]$.

$$
Z^{(1)}=(-0.1265,-0.2110,-0.2945,-0.3780)
$$

d. The least squares method is used to estimate parameters $\mathrm{a}$ and $\mathrm{b}$, and the parameter $\hat{\alpha}=(\hat{a}, \hat{b})^{T}$ is:

$$
\hat{\alpha}=(\hat{a}, \hat{b})^{T}=\left(B^{T} B\right)^{-1} B^{T} Y=(0.004785,0.085208)^{T}
$$

Among them, $B=\left[\begin{array}{ll}-1.4315 & 1.0000 \\ -0.2110 & 1.0000 \\ -0.2945 & 1.0000 \\ -0.3780 & 1.0000\end{array}\right], Y=\left[\begin{array}{l}0.085 \\ 0.084 \\ 0.083 \\ 0.084\end{array}\right]$

e. The time response function of the differentiation of the whitening equation is

$$
\hat{x}^{(1)}(t)=\left[x^{(1)}(1)-\frac{b}{a}\right] e^{-a(t-1)}+\frac{b}{a}
$$

It is discretized into a time response sequence

$$
x^{(1)}(k)=\sum_{i=1}^{k} x^{(0)}(i), k \in(1,2, \cdots, n)
$$

$$
\stackrel{\wedge}{X}^{(1)}=[0.0840,0.1686,0.2528,0.3366,0.4200]
$$

f. $\stackrel{\wedge}{X}^{(1)}$ is a modeling prediction sequence based on $x^{(0)}(k)=x^{(1)}(k)-x^{(0)}(k-1), 2 \leq k \leq n$. A reduction of $\hat{X}^{(1)}$ is used to get the fitting value of raw data $\hat{X}^{(0)}$.

$$
\stackrel{(}{X}^{(0)}=[0.0840,0.0846,0.0842,0.0838,0.0834,0.0830,0.0826,0.0822]
$$




\section{B. Prediction Results}

We compare the raw data and predicted data of parameter A, as shown in Table 2.
Similarly, grey prediction can be used to predict other performance parameters of the missile.

TABLE II. WARHEAD-PARAMETER A DATA PREDICTION COMPARISON

\begin{tabular}{cccccccc}
\hline & first & second & third & fourth & fifth & first year of & second year of \\
prediction & third year of \\
prediction & year & year & year & year & pediction \\
\hline raw data & 0.084 & 0.085 & 0.084 & 0.083 & 0.084 & & \\
prediction data & 0.0840 & 0.0846 & 0.0842 & 0.0838 & 0.0834 & 0.0830 & 0.0826 \\
residual & 0.0000 & -0.0004 & 0.0002 & 0.0008 & -0.0006 & & 0.0822 \\
\hline
\end{tabular}

\section{Quality Status Assessment of Subsystems} BASED ON LINEAR WEIGHTED COMPREHENSIVE EVALUATION

The performance quality assessment of the missile subsystems depends not only on the performance parameters, but also in the comprehensive consideration of the service resume and appearance information, which are mainly derived from the daily management and storage. Taking a missile warhead as an example, the evaluation system of warhead performance quality status is established, as shown in Figure 2. The linear weighted comprehensive evaluation method is applied to evaluate its performance and quality.

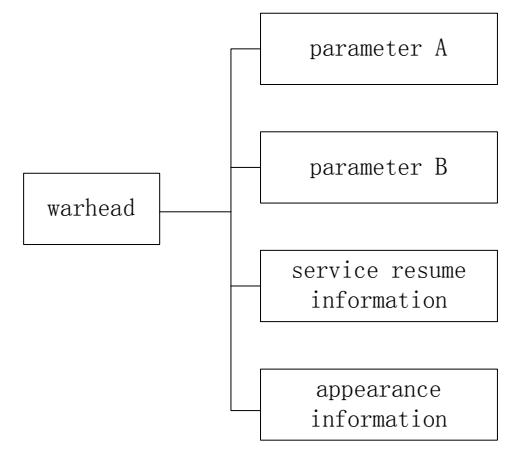

FIGURE II. WARHEAD EVALUATION INDEX SYSTEM

Select a set of data from the previous test data:

$$
X=\left(x_{1}, x_{2}, x_{3}, x_{4}\right)^{T}=(0.7000,0.9142,0.9933,0.9672)^{T}
$$

The weight coefficients corresponding to the parameters of each parameter are:

$$
W=\left(w_{1}, w_{2}, w_{3}, w_{4}\right)=(0.2632,0.4500,0.0752,0.2116)
$$

Using linear function

$$
y=F(\boldsymbol{W}, \boldsymbol{X})=\sum_{i=1}^{m} w_{i} x_{i}
$$

By calculation, $\mathrm{y}=0.8750$.

Among them: $y$ represents the joint evaluation value, $x_{i} \quad(i=1,2, \cdots, m)$ is the evaluation value of each evaluation index data, and $w_{i}(i=1,2, \cdots, m)$ is the weight coefficient of each evaluation index parameter $\left(0 \leq w_{i} \leq 1, \sum_{i=1}^{m} w_{i}=1\right)$.

In the same way, on the basis of the parameters of the grey prediction, combined with the daily management and storage information, the evaluation value of the performance quality of other subsystems can be obtained by using the linear weighted comprehensive evaluation method.

\section{Prediction of Performance Quality Status of THe Whole Missile System Based on SVM}

\section{A. Prediction Ideas of SVM}

First, we establish a one-to-one correspondence between the hitting effect of missile such as the landing point CEP and the quality level of the whole missile system. According to the results of the live launching, the whole missile system is divided into excellent, good, general and unqualified, and it is used as the output of SVM. Performance quality status evaluation of subsystems before launch is used as input of SVM. The input and output of a one-to-one corresponding support vector machine are established on the basis of the information before and after missiles' live launching. Then we use the sample data to train the support vector machine to determine the penalty factor and kernel function. Finally, the performance quality assessment results of subsystems of the missile to be launched are put into the established support vector machine prediction model to predicte the performance quality status of the whole missile system

\section{B. SVM Modeling}

When using SVM modeling, the training sample is mapped to a high dimensional space by inner product kernel function. In this high dimensional space, the maximum classification hyperplane is established. SVM improves its generalization ability by searching the least risk structure to improve its generalization ability[4]. The mapping of nonlinear data to high dimensional space is shown in Figure 3. Generally speaking, the essence of SVM is the two class classification problem, which can be regarded as a linear classifier to find the maximum classification interval in a feature space, which maximizes the classification interval. 


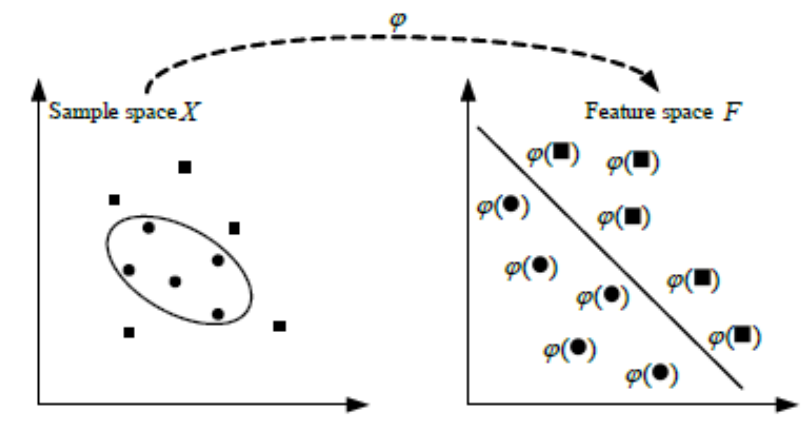

FIGURE III. MAPPING NONLINEAR DATA TO HIGH DIMENSIONAL SPATIAL SCHEMATIC DIAGRAM

In support vector machines, the main parameters that mainly affect their learning efficiency and generalization ability are the value of the penalty factor $\mathrm{c}$ and the kernel function parameter $\mathrm{g}$, but the support vector machine does not provide a simple method to select the two parameters well. In the practical application, chaos optimization, genetic algorithm and grid search are generally used to search for the optimal parameter of support vector machines[5]. The chaotic optimization and genetic algorithms are applicable to the processing of large sample data, but the optimal parameters are uncertain, and the optimal parameters can not be obtained. The grid search method can search all the parameters within the specified range, and can determine the optimal parameters, so it is suitable for the processing of small sample data, but the prediction rate is slow. For missile such special equipment, the number of firing rounds is not very large, and the available samples are relatively few. Therefore, grid search method is adopted here.

The basic principle of grid search method is to find all the required parameter combinations in a given rectangular range according to the given step size. The specific steps are as follows[6]:

Step 1: The values of $\mathrm{c}$ and $\mathrm{g}$ in grid search are set in a reasonable range and the corresponding step length is determined. At this point, a two-dimensional grid is constructed on the coordinate system of $\mathrm{c}$ and $\mathrm{g}$.

Step 2: A pair of parameters $(\mathrm{c}, \mathrm{g})$ is extracted from the constructed coordinate system, and the training samples are trained by LIBSVM software, then the test sample is used to predict the support vector machine, and the accuracy rate is recorded.

Step 3: Repeat Step 2 until all parameter combinations in the two-dimensional mesh are trained once.

Step 4: Finally, all parameters are represented by contour lines $(\mathrm{c}, \mathrm{g})$, and the best values of $\mathrm{c}$ and $\mathrm{g}$ are determined.

When using SVM to predict the performance quality of a certain type of missile, 15 input nodes, that is, the performance quality assessment value of 15 subsystems, and 4 output nodes, are "1,2,3,4", representing "excellent, good, general and unqualified".

\section{Performance Quality Status Prediction}

Using 26 launched missiles in Table 3 as learning samples, the missile performance quality status prediction model is constructed by LIBSVM software. In Table 4, 4 launched missiles are tested samples. The penalty factor $\mathrm{c}$ and kernel function parameter $\mathrm{g}$ obtained by grid search method and its contour lines are shown in Figure 4. $c=0.00097656, \mathrm{~g}=64$ can be seen from the diagram. The recognition rate is $100 \%$.

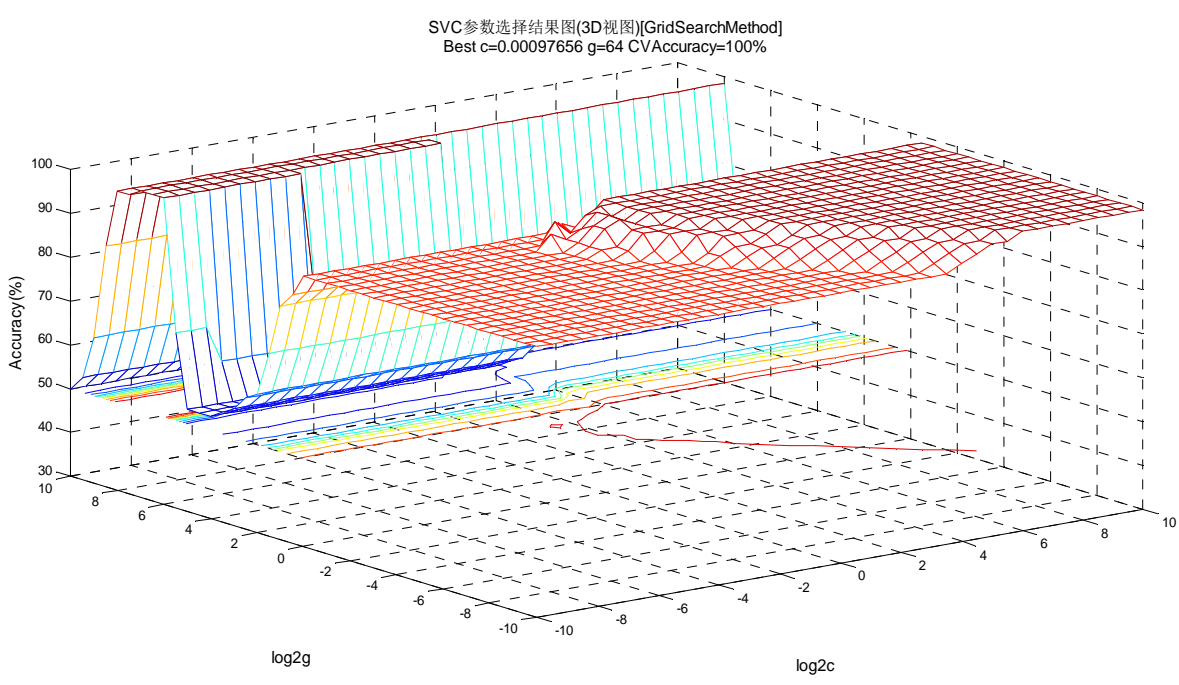

FIGURE IV. THE CONTOUR MAP OF THE PARAMETER PAIR $(\mathrm{C}, \mathrm{G})$ 
TABLE III. PERFORMANCE QUALITY STATUS EVALUATION OF 26 MISSILES LAUNCHED BY A DEPARTMENT

\begin{tabular}{|c|c|c|c|c|c|c|c|c|c|c|c|c|c|c|c|c|c|}
\hline number & $\begin{array}{l}\text { status } \\
\text { level }\end{array}$ & $\begin{array}{l}\text { the } \\
\text { whole } \\
\text { missile } \\
\text { system }\end{array}$ & $\mathrm{I}_{1}$ & $\mathrm{I}_{2}$ & $\mathrm{I}_{3}$ & $\mathrm{I}_{4}$ & $\mathrm{I}_{5}$ & $\mathrm{I}_{6}$ & $\mathrm{I}_{7}$ & $\mathrm{I}_{8}$ & $\mathrm{I}_{9}$ & $\mathrm{I}_{10}$ & $\mathrm{I}_{11}$ & $\mathrm{I}_{12}$ & $\mathrm{I}_{13}$ & $\mathrm{I}_{14}$ & $\mathrm{I}_{15}$ \\
\hline 1 & excellent & 09161 & 0.9374 & 09305 & 0.7343 & 0.7465 & 0.9110 & 09143 & 0.9247 & 0.9343 & 0.9273 & 0.9254 & 0.7597 & 0.9308 & 0.8311 & 0.8729 & 0.9686 \\
\hline 2 & excellent & 0.9151 & 0.9667 & 0.9029 & 0.8352 & 0.7465 & 0.8979 & 0.9317 & 0.9339 & 0.9167 & 0.9296 & 0.9356 & 0.7597 & 0.9440 & 0.8495 & 0.8840 & 09719 \\
\hline 3 & excellent & 09191 & 09391 & 09305 & 0.7843 & 0.7463 & 0.8976 & 0.9318 & 0.9343 & 09369 & 0.9262 & 0.9350 & 0.7597 & 0.9286 & 0.8463 & 0.8658 & 0.9543 \\
\hline 4 & excellent & 09103 & 0.9517 & 09032 & 0.8475 & 0.7465 & 0.8990 & 09175 & 0.9257 & 09316 & 0.9288 & 0.9272 & 0.7597 & 0.9160 & 0.8467 & 0.8698 & 0.9619 \\
\hline 5 & excellent & 0.9214 & 0.9457 & 0.9391 & 0.7822 & 0.7465 & 0.8898 & 0.9207 & 0.9352 & 0.9313 & 0.9271 & 0.9353 & 0.7597 & 09349 & 0.8189 & 0.8678 & 0.9235 \\
\hline 6 & excellent & 09103 & 09591 & 0.9006 & 0.7831 & 0.7465 & 0.9169 & 0.9304 & 0.9360 & 0.9330 & 0.9275 & 0.9254 & 0.7597 & 0.9416 & 0.8290 & 0.8755 & 09737 \\
\hline 7 & good & 0.9041 & 09667 & 0.8921 & 0.7460 & 0.7463 & 0.9166 & 0.9305 & 0.9341 & 0.9299 & 0.9249 & 0.9350 & 0.7597 & 0.9303 & 0.8514 & 0.8587 & 09468 \\
\hline 8 & good & 0.9058 & 0.9667 & 0.8973 & 0.7555 & 0.7465 & 0.8742 & 0.9281 & 0.9349 & 0.9381 & 0.9254 & 0.9351 & 0.7597 & 0.9109 & 0.8450 & 0.8698 & 0.9423 \\
\hline 9 & good & 0.9097 & 09245 & 0.9305 & 0.6275 & 0.7465 & 0.8382 & 0.9306 & 0.9356 & 0.9380 & 0.9284 & 0.9265 & 0.7597 & 0.9298 & 0.8440 & 0.8750 & 0.9695 \\
\hline 10 & good & 0.9073 & 09386 & 0.9029 & 0.7138 & 0.7872 & 0.8948 & 0.9415 & 09454 & 0.9227 & 0.9288 & 0.9437 & 0.8150 & 09320 & 0.8367 & 0.8891 & 09767 \\
\hline 11 & good & 0.9027 & 09667 & 0.8900 & 0.6972 & 0.7465 & 0.9024 & 09316 & 09362 & 0.9368 & 0.9279 & 0.9357 & 0.7597 & 0.9391 & 0.8479 & 0.8684 & 0.9696 \\
\hline 12 & good & 0.9007 & 09425 & 09050 & 0.6073 & 0.7465 & 0.9061 & 09309 & 09357 & 0.9270 & 0.9281 & 0.9357 & 0.7597 & 0.9157 & 0.8429 & 0.8684 & 0.9568 \\
\hline 13 & good & 0.9078 & 09667 & 0.8983 & 0.8150 & 0.6822 & 0.8987 & 09120 & 09168 & 0.9371 & 0.9291 & 0.9235 & 0.7597 & 0.9224 & 0.8387 & 0.8840 & 0.9583 \\
\hline 14 & good & 0.9045 & 0.9321 & 09050 & 0.7786 & 0.7465 & 0.9454 & 09140 & 0.9249 & 0.9382 & 0.9270 & 0.9268 & 0.7597 & 0.9329 & 0.8269 & 0.8755 & 09324 \\
\hline 15 & good & 0.9056 & 09258 & 09050 & 0.7924 & 0.7462 & 0.8680 & 0.9297 & 0.9342 & 09144 & 0.9274 & 0.9266 & 0.7597 & 0.9262 & 0.8539 & 0.8820 & 09630 \\
\hline 16 & good & 0.9032 & 0.9251 & 09050 & 0.7587 & 0.7464 & 0.9045 & 09327 & 09363 & 0.9350 & 0.9270 & 0.9351 & 0.7597 & 0.9260 & 0.8342 & 0.8604 & 0.9432 \\
\hline 17 & good & 0.9016 & 0.9303 & 0.9050 & 0.7014 & 0.7464 & 0.8905 & 0.9280 & 0.9357 & 0.9367 & 0.9255 & 0.9354 & 0.7597 & 0.9239 & 0.8477 & 0.8412 & 0.9737 \\
\hline 18 & general & 0.8982 & 09412 & 0.8900 & 0.7673 & 0.7465 & 0.9012 & 09146 & 0.9245 & 0.9365 & 0.9275 & 0.9265 & 0.7597 & 0.9275 & 0.8386 & 0.8678 & 0.9506 \\
\hline 19 & general & 0.8958 & 0.9062 & 09007 & 0.7730 & 0.7037 & 0.9001 & 0.9161 & 0.9250 & 0.9354 & 0.9277 & 0.9266 & 0.7597 & 09375 & 0.8384 & 0.8503 & 0.9452 \\
\hline 20 & general & 0.8695 & 0.9152 & 0.8348 & 0.7738 & 0.7872 & 0.8984 & 0.9132 & 0.9250 & 0.9318 & 0.9269 & 0.9266 & 0.8150 & 0.9317 & 0.8320 & 0.8703 & 0.9583 \\
\hline 21 & general & 0.8891 & 0.8816 & 0.8921 & 0.8121 & 0.7465 & 0.8877 & 09324 & 0.9361 & 09160 & 0.9281 & 0.9351 & 0.7597 & 09360 & 0.8465 & 0.7906 & 0.9555 \\
\hline 22 & general & 0.8951 & 0.9106 & 0.9050 & 0.6450 & 0.7465 & 0.8834 & 0.9312 & 0.9352 & 0.9355 & 0.9285 & 0.9352 & 0.7597 & 0.9379 & 0.8260 & 0.8613 & 0.9346 \\
\hline 23 & geneal & 0.8843 & 0.9234 & 0.8709 & 0.6680 & 0.7464 & 0.8998 & 0.9305 & 0.9357 & 0.9376 & 0.9263 & 0.9357 & 0.7597 & 0.9134 & 0.8360 & 0.8752 & 0.9570 \\
\hline 24 & general & 0.8857 & 09232 & 0.8709 & 0.6642 & 0.7465 & 0.9273 & 09318 & 09358 & 0.9371 & 0.9254 & 0.9362 & 0.7597 & 0.9314 & 0.8607 & 0.8698 & 09701 \\
\hline 25 & general & 0.8872 & 09198 & 0.8709 & 0.7320 & 0.7484 & 0.8955 & 09306 & 09351 & 0.9387 & 0.9253 & 0.9350 & 0.7597 & 09419 & 0.8697 & 0.8678 & 0.9673 \\
\hline 26 & general & 0.8909 & 0.9526 & 0.8624 & 0.8034 & 0.7463 & 0.8625 & 0.9314 & 0.9351 & 0.9377 & 0.9256 & 0.9352 & 0.7597 & 0.9408 & 0.8411 & 0.8821 & 0.9572 \\
\hline
\end{tabular}

TABLE IV. PERFORMANCE QUALITY STATUS EVALUATION OF 4 MISSILES LAUNCHED BY A DEPARTMENT

\begin{tabular}{|c|c|c|c|c|c|c|c|c|c|c|c|c|c|c|c|c|c|}
\hline number & $\begin{array}{l}\text { status } \\
\text { level }\end{array}$ & $\begin{array}{l}\text { the } \\
\text { whole } \\
\text { missile } \\
\text { system }\end{array}$ & $\mathrm{I}_{1}$ & $\mathrm{I}_{2}$ & $\mathrm{I}_{3}$ & $\mathrm{I}_{4}$ & $\mathrm{I}_{5}$ & $\mathrm{I}_{6}$ & $\mathrm{I}_{7}$ & $\mathrm{I}_{8}$ & $\mathrm{I}_{9}$ & $\mathrm{I}_{10}$ & $\mathrm{I}_{11}$ & $\mathrm{I}_{12}$ & $\mathrm{I}_{13}$ & $\mathrm{I}_{14}$ & $\mathrm{I}_{15}$ \\
\hline 28 & good & 0.9097 & 0.9574 & 0.8983 & 0.7595 & 0.7872 & 0.8986 & 0.9408 & 09454 & 0.9308 & 0.9281 & 0.9449 & 0.8150 & 0.9469 & 0.8520 & 0.8778 & 0.9651 \\
\hline 29 & good & 0.9041 & 0.9613 & 0.8966 & 0.7263 & 0.7465 & 0.9004 & 09166 & 09254 & 0.9371 & 0.9281 & 0.9265 & 0.7597 & 0.9370 & 0.8459 & 0.8698 & 09660 \\
\hline 30 & general & 0.8878 & 0.9103 & 0.8709 & 0.8128 & 0.7251 & 0.8927 & 0.9323 & 09356 & 0.9316 & 0.9272 & 0.9344 & 0.7597 & 0.9366 & 0.8277 & 0.8769 & 0.9524 \\
\hline
\end{tabular}

After testing the samples, it is found that the predicted results of the 4 missiles are consistent with the actual results, as shown in Table 5.

TABLE V. PREDICTION RESULTS OF SVM MODEL

\begin{tabular}{cccc}
\hline number & $\begin{array}{c}\text { prediction results } \\
\text { of SVM }\end{array}$ & $\begin{array}{c}\text { prediction level } \\
\text { of SVM }\end{array}$ & $\begin{array}{c}\text { Actual status } \\
\text { level }\end{array}$ \\
\hline 27 & 1 & excellent & excellent \\
28 & 2 & good & good \\
29 & 2 & good & good \\
30 & 3 & general & general \\
Prediction & & $100 \%$ & - \\
accuracy & & & \\
\hline
\end{tabular}




\section{CONCLUSION}

In the future joint operations, the missile force must face large-scale and efficient operations, which requires that the missile force has the ability to launch mass missiles quickly and accurately. But in the current practice of real missile launch, the traditional method of testing qualified first is usually adopted, although it can guarantee the effect of missile strike, but it is difficult to meet the needs of the real battlefield In this paper, based on the test data of missile performance parameters and daily management and storage information, using grey theory and linear weighted comprehensive evaluation method, the missile performance parameters are predicted and subsystems performance quality status are evaluated. Finally, on the basis of the in-depth study of the actual missile launch information, Support vector machine (SVM) is used to predict the quality status of whole missile, which provides a way to predict the performance quality of missile. The example shows that this method can accurately predict the performance quality status of missile.

\section{REFERENCES}

[1] Si-feng Liu, Nai-ming Xie. Grey Systems: Theory and Application [M]. Beijing: Science Press, 2008.

[2] Ju-long Deng. Foundation of GreyTheory [M]. Wuhan: Huazhong University of Science and Technology Press, 2002.

[3] Wen-jian Wang, Chang-qian Men. Support Vector Machine Modeling and Application [M]. Beijing: Science Press, 2014.

[4] Jian-feng Wang, Lei Zhang, Guoxing Chen. A parameter optimization method for an SVM based on improved grid search algorithm [J]. Applied Science an Technology, 2012 (3): 28-31.

[5] Dao-wen Liu, Hai-na Hu. Network traffic prediction based on grid search SVM method [J]. Computer Application and Software, 2012 (11): 185-186.

[6] Chao Guo, Wei-hua Song, Wei Wei. Stope roof stability prediction based on both SVM and grid-search method [J]. China Safety Science Journal, 2014, 24 (8). 